risk and well within the $95 \%$ confidence interval for our estimate (which should have read 1.8 to 25.6 not 1.8 to $2 \cdot 6$ as published). These wide limits reflect the small size of the control group but there is no reason to suppose that the lower limit of risk would have disappeared if the total number of controls had been larger.

The constraints of writing a short report prevented further amplification of the results and discussion. It is clear, however, from the data on individual groups of conditions related to the wearing of lenses that the relative risks were highest for soft lenses in every case, except for abrasions related to lens wear, which are a well known and minor hazard of wearing hard lenses. Extended wear soft lenses showed a higher risk than daily wear soft lenses for the remaining groups of disorders except toxic and hypersensitivity reactions, although the $95 \%$ confidence intervals were wide. The controls used for these estimates of relative risk, as opposed to the risk for all disorders, were all the patients in the study who were not affected by the condition in question although they may or may not have had another disease related to lens wear. For these estimates the minimum number of controls for any one type of lens was 32 .

We have pointed out that population based controls are needed to confirm these findings, as suggested by Dr Tulley. We are carrying out a similar study, which is already larger, and are seeking funds to carry out a population based survey after recruiting hospital based cases and controls. To obtain at least 100 wearers of extended wear soft lenses, however, we estimate that 18000 subjects in our catchment area will have to be interviewed.

WENDY A FRANKS

G G W ADAMS

J K G DART

D MINASSIAN

nstitute of Ophthalmology

London WCIH 9QS

\section{The nation's health}

I suppose we should be grateful for an editorial on our report The Nation's Health (24 September, p 749), although your invitation to Professor J C A Mitchell, a general physician, to review a report on public health seems an eccentric precedent. May we expect future reviews of cardiological works to be written by proctologists? Another circumstance, which may not be a precedent, is that Professor Mitchell's review was apparently made available to the general press in advance of publication, although no similar courtesy was extended to the report's authors.

Professor Mitchell makes three main hostile points. Firstly, he finds a lack of perspective and cites as examples the report's reference to the prevention of war and to possible hazards from visual display units. The prevention of war occupies 14 lines in the introduction and the possible hazards of visual display units two, in which the evidence is briefly summarised as inconclusive. Together these items occupy very much less than half a page in a 331 page report.

Secondly, he refers to "surprising errors" but cites only one-a misprint in which we quote the yearly number of deaths from stroke as 22000 instead of 72000 .

Thirdly, he accuses us of a lack of logic when we note a rise in the number of abortions and an increased control of fertility. Professor Mitchell is obviously unaware of the technical meaning of the term fertility. Similarly, he displays a difficulty he has shown before in failing to understand the difference between the likely effect of lowering the blood pressure of a population and of treating patients with clinical hypertension. The choice of a more appropriate reviewer might have avoided these misunderstandings.

Professor Mitchell would like us to have confined our attention to a smaller number of objectives. He quotes at length and with apparent approval-although without attribution - from a major chapter on inequalities in health while implying that we neglect this issue and seems not to have noticed the report's heavy concentration on tobacco and alcohol, which he rightly believes to pose particularly important public health problems. He would have liked us to make more use of international comparisons, but he wishes that we had not drawn attention to this country's comparatively poor record. He is certainly hard to please.

Finally, Professor Mitchell is clearly not familiar with the published work on the World Health Organisation's strategy of Health for All by the Year 2000 and its strong emphasis on what is unequivocally feasible. We were guided by this principle in selecting 11 priorities based mainly on the successful experience of other countries whose recent health records have been better than ours. We hope that some of your readers may actually read the report and decide its merits for themselves.

ALWYN SMITH BOBBIE JACOBSON

Department of Epidemiology and Social Oncology,

Christie Hospital and Holt Radium Institute,

Manchester M20 9QL

\section{Ectopic pregnancy}

Professor John Newton (10 September, p 633) discussed a steep increase in the rate of ectopic pregnancy in industrialised countries. $\mathrm{He}$ was unable to cite British figures as they were unavailable. Though this may be true of England and perhaps of Wales, in Scotland $100 \%$ episode records for general and maternity hospital discharges show that there has been a $51 \%$ increase in the rate of ectopic pregnancy since 1970-2, a much smaller rise than the fourfold increase quoted for the United States (table).

Numbers of ectopic pregnancies, rates of ectopic pregnancy per 1000 pregnancies, and case fatality rates per 1000 ectopic pregnancies in Scotland, 1970-86

\begin{tabular}{lccc}
\hline Year & $\begin{array}{c}\text { No of } \\
\text { ectopic } \\
\text { pregnancies }\end{array}$ & $\begin{array}{c}\text { Rate/ } \\
\text { 1000 known } \\
\text { pregnancies }\end{array}$ & $\begin{array}{c}\text { Case fatality } \\
\text { rate/ } \\
1000 \text { ectopic } \\
\text { pregnancies }\end{array}$ \\
\hline $1970-2$ & 1272 & $4 \cdot 3$ & $2 \cdot 4$ \\
$1973-5$ & 1188 & $4 \cdot 6$ & $3 \cdot 4$ \\
$1976-8$ & 1306 & $5 \cdot 5$ & $1 \cdot 5$ \\
$1979-81$ & 1372 & $5 \cdot 4$ & $0 \cdot 7$ \\
$1982-4$ & 1544 & $6 \cdot 3$ & $1 \cdot 3$ \\
$1985-6$ & 1101 & $6 \cdot 5$ & $2 \cdot 7$ \\
\hline
\end{tabular}

*All hospital admissions for spontaneous and therapeutic abortions added to total births.

Between 1970 and 1986 there were 15 deaths with a registered underlying cause of ectopic pregnancy, and, although the numbers are small, the three year case fatality rates indicate that though the rate fell in the last half of the 'seventies, it rose in the $1980 \mathrm{~s}$.

SUSAN COLE

JOHN A CLARKE

Information and Statistics Division

Scottish Health Services Common Services Agency,

Trinity Park House.

Edinburgh EH5 3SQ

\section{Starving outpatients}

I wonder how many of my colleagues, particularly those in psychiatric and geriatric specialties, would recognise the following situation.
Currently we have over 400 people attending our community care (depot) clinic, as well as numerous other psychiatric outpatient clinics, most of whom are entirely dependent on some kind of social security provision. With the postal strike and the recent changes in legislation, however, many of them now simply do not have enough money to live on. As a result they are coming to the outpatient clinics or for their treatment nearly starving. The staff in the clinic find that they need to provide people with hot drinks, food, and cigarettes just to keep them reasonably stable and persuade them to take their regular treatment. In fact, it makes sense to some patients to discontinue treatment because at least in that way they can become ill in more florid ways and thus benefit from the shelter, warmth, and food of admission to the acute psychiatric unit. As winter comes on I suspect that this process will more and more become the only sensible option for some extremely poor patients.

Of course, working in quite a deprived inner city area such as Hackney we may be seeing something rather special, which is not reflected in other parts of the country. Nevertheless, I wonder if other units are experiencing the same problem and how they are coping with it. In particular, are there any mechanisms for obtaining money or food that people can invoke, given that such a regular need is beyond the capacity of our extremely concerned league of friends, that we have two vacancies for social workers because the positions have not been advertised (probably as a money saving exercise), and that the notion of a loan in this context is unrealistic?

Department of Psychological Medicine,

Hackney Hospital,

London $\mathrm{E} 96 \mathrm{BE}$

\section{Intravenous $\beta$ agonist in severe acute asthma}

The study by Dr B Cheong and others was designed to compare the efficacy of intravenous and nebulised salbutamol in the management of severe acute asthma (13 August, p 448).

Nearly 2000 people die of asthma each year in the United Kingdom, and most of these deaths occur within the first few hours of a severe attack. This was therefore an important study, but several features raise doubts about its conclusion.

Firstly, in the nebulised group the patients were given salbutamol at 30 minutes and again at two hours, whereas in the intravenous group the infusion was started at 30 minutes and continued until the end of four hours. Secondly, table II indicates that the peak flow response was not significantly different at two and half hours in the two groups and that the differences became significant only after this time. Thirdly, table III shows a decrease in the pulse rate at two and half hours onwards in the nebulised group and thereby indicates a declining effect of salbutamol in the nebulised group. Finally, the oxygen and carbon dioxide tensions in the arterial blood are important objective measurements in the management of severe acute asthma. No comparison of these was made between the nebulised and intravenous groups after treatment. The conclusion of greater benefit from intravenous than from nebulised salbutamol cannot therefore be sustained.

P K MISHRA O P GALPIN

Llandudno General Hospital

Llandudno LL30 $1 \mathrm{LB}$

Dr B Cheong and others concluded that "intravenous salbutamol is more effective than nebulised salbutamol in acute severe asthma but may have 